\title{
What Determines the Change of Lakes in Large Cities under Climate Change and Anthropogenic Activities? Evidence from Eastern China
}

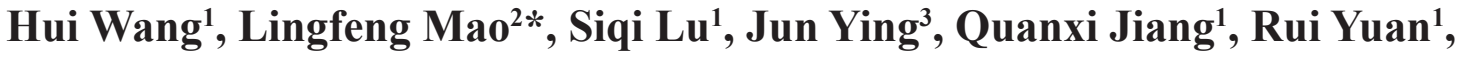 \\ Xiaofeng Liu', Min Wang', Dan Zhao ${ }^{5}$ \\ ${ }^{1}$ College of Landscape Architecture, Nanjing Forestry University, Nanjing, China \\ ${ }^{2}$ Joint Innovation Center for Sustainable Forestry in Southern China, College of Biology and the Environment, \\ Nanjing Forestry University, Nanjing, China \\ ${ }^{3}$ School of Landscape Architecture, Zhejiang Agriculture and Forestry University, Lin'an, China \\ ${ }^{4}$ College of Architecture and Urban Planning, Tongji University, Shanghai, China \\ ${ }^{5}$ College of Earth Sciences, Chengdu University of Technology, Chengdu, China
}

Received: 26 January 2018

Accepted: 24 April 2018

\begin{abstract}
Lakes are one of the most important wetland types on the earth with many ecosystem functions. With continuing economic growth and climate change, lake abundance and surface areas throughout the world have been threatened by many factors, including by human and environmental disruptions. However, we still have limited knowledge on how human activities and climate change affect lake reductions and associated ecosystem services. Elucidating the underlying mechanisms of lake shrinkage will help maintain an ecological balance in urban planning, especially in rapidly developing countries. We explore the determinants of lake shrinkage and abundance reduction from the 1980s to the 2010s using remote sensing data of lakes in two large cities in eastern China: Nanchang and Shanghai. In order to account for the non-independence of time-series data, time series auto-regressive generalized least squares (GLS) models were used to examine the relationship between lake area/abundance and human activities and climate change. Our results show that human activities rather than climate change, are the most important determinants for the areas and numbers of lake shrinkage, and gross domestic product (GDP) and population size could explain more than half of the variation in the number and area of lakes with areas larger than 20 ha in the two cities. GDP and lake area shrinkage do not exhibit a linear relationship. This highlights the importance of wetland protection in the early development stage. Because the main determinants are human activities, cities have the ability to protect wetlands via suitable planning.
\end{abstract}

Keywords: wetlands, water resources, urbanization, human disturbance, economic development

*e-mail: maolingfeng2008@163.com 


\section{Introduction}

Wetlands are among the most important ecosystem types in the world and provide a multitude of important ecosystem functions, including biodiversity conservation, carbon sinking, habitat provision, pollutant removal, and flood water storage [1-3]. However, wetlands throughout the world have been reduced and degraded due to human disruptions and climate change [4], e.g., lakes in the Mongolian Plateau [5]. But until recently few studies have focused on wetlands in the cities. Unlikely wetlands in relative intact areas, they are potentially impacted by human disturbances more intensively, such as water consumption for economic development, water use by the population, and the land cover change [6-8]. With the rapid development of cities and the intensification of human disturbance, evidence indicates that the global hydrological cycles have changed due to climate and human consumption $[6,9,10]$. Wetlands have also been impacted by climate change and anthropogenic activities such as urbanization [11]. Moreover, climate change could potentially affect water use in cities [12, 13]. Thus, uncovering the mechanisms of wetland shrinkage is important to urban planning and wetland conservation.

China is the largest developing country and its economy developed very swiftly over the past three decades with critical challenges [14]. Also, the environment and the structure of the economy changed in this period. Meanwhile, sufficient evidence has indicated that the climate in China also changed during this period against the backdrop of global climate change [15]. In China, urban areas contain $40 \%$ of the population and $75 \%$ of the economic activity [16]. Eastern cities in China typically have long industrial development histories and face severe challenges with regard to natural resources and pollution [6, 16, 17]. Also, for instance, land cover in and around these cities has been changed dramatically [18]. It thus impacts the distribution and size of surface water. As a most important wetland type, lakes have special ecosystem functions [19]. Using the data from the cities in this area could help elucidate the determinants of lake shrinkage generally in the rapid development in China. Until recently, we still have limited knowledge on the driving factors of lake change and its underlying mechanisms. Specifically, we do not know the relative importance of climate change and anthropogenic activities affecting these changes.

Herein, we use changes in the number and area of lakes in two large cities in China, climate data (i.e., mean annual temperature and annual precipitation), and anthropogenic factors (i.e., population size, GDP) from the 1980s to the 2010s to explore a basic scientific question about whether climate or anthropogenic activities affect lake shrinkage. Given that each city may have different mechanisms underlying lake shrinkage, we used two representative cities to explore our hypotheses, Shanghai and Nanchang, located in typical rapid development areas in China.

\section{Material and Methods}

\section{Materials}

Shanghai is the largest city and the paramount economy in China. Nanchang is a swiftly developing city as well as the largest city and capital in Jiangxi Province. The two cities what we used are very typical cities in the economic development of China, which can represent the biggest cities (such as Shanghai, Beijing, and Guangzhou) and the second city groups with very fast economic development (such as Hangzhou, Nanjing, and Xiamen). The research areas for these two cities covered all administrative regions of the cities, i.e., $7400 \mathrm{~km}^{2}$ and $6300 \mathrm{~km}^{2}$ for Nanchang and Shanghai, respectively (Fig. 1).

We used remote sensing images from Landsat TM (http://glovis.usgs.gov/) that were taken during the 1980s to 2010s for two eastern cities in China. Considering the influence of seasonal variation, we limited most of the images to those taken from April to October. Because the remote sensing data for some years in this season are not available due to missing images and high-ratio cloud coverage (higher than 10\%), we used the nearest high-quality images given the available data (Appendix Table S1 and Table S2). We also detected and deleted wetlands associated with rivers since our study focuses on lakes. This is because the rivers may

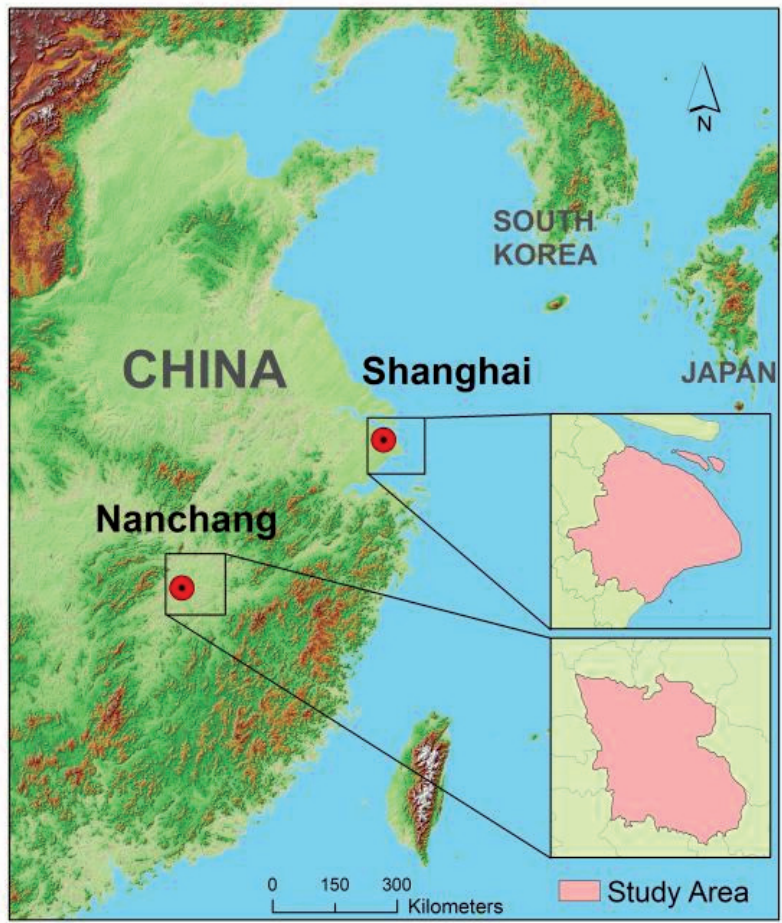

Fig. 1. Locations of the two cities. 
potentially be influenced by the factors out of cities dramatically rather than only the local factors. To reduce the lake identification bias from the satellite images, we only identified lakes with areas larger than 0.5 ha. Meanwhile, we divided all lakes into three groups based on their area (i.e., 0.5 ha-10 ha, 10 ha-20 ha, and larger than $20 \mathrm{ha}$ ) to explore the effects on different sizes. The normalized difference water index (NDWI) was used to calculate the surface area of water. When the value was less than 0 , we considered the coverage as water-free surface [5]. This method is robust for water surface area calculations [5]. The equation is as follows. The spatial images operations and calculations were performed in ENVI and ArcGIS 10.2 (ESRI, Inc.).

$$
\text { NDWI }=(\text { Band2-Band5)/(Band2+Band5 })
$$

Population size is related to natural resource consumption, including water - the most important and basic resource for survival and development [9]. Meanwhile, the size and structure of the economy can potentially influence water consumption [6] and subsequently influence the degree of wetland disturbance. Thus, we used the population size of each city and their gross domestic product (GDP) to explore the effects of human activities on wetlands. Additionally, the sizes of primary industry (GDP1), secondary industry (GDP2), and tertiary industry (GDP3) were used to indicate the effects of economic structure on lake shrinkage. The GDP1 mainly refers to the planting industry, forestry, animal husbandry, etc.; GDP2 mainly refers to industries of processing and manufacturing; and GDP3 refers to the industries except the ones in GDP1 and GDP2, such as education and catering (National Industries Classification of China, GB/T47542017). The GDP and population size data sets were from annual inspections (http://www.yearbookchina.com; www.shanghai.gov.cn)

We used relatively broad climatic indicators, i.e., mean annual temperature and precipitation, to correlate with the surface area of lakes. Climate data were from the meteorological database of the China Meteorological Administration (http://cdc.nmic.cn/ home.do). The climate data sets were from the records of the nearest meteorological station to the center of the cities.

\section{Statistical Analyses}

Since most of the lake areas were contributed by lakes larger than 20 ha, we first evaluated the trends of GDP and lake areas for these lakes for Nanchang and Shanghai, respectively (Fig. 2). Because timeseries data may not be independent [20] except for using ordinary least squares (OLS) models, we also used auto-regressive generalized least squares (GLS) models for investigated variables and lake area/ abundance to reduce the influence from potential data non-independence. To evaluate the relative importance of effects of human actives (i.e., GDP and population size) and climate changes (i.e., annual precipitation and mean annual temperature), we compared the values of Akaike Information Criterion (AIC; Akaike 1974) [21] and pseudo-r ${ }^{2}$ of GLS models for each factor (Table 1). Before these analyses, we performed natural logarithm transformations on all data to normalize distributions. To explore the non-linear relationship between GDP and lake areas for lakes larger than 20 ha, we also used non-linear OLS and GLS to estimate the fitted lines (Fig. 3). All analyses were performed using the $\mathrm{R}$ program [22]. The GLS models were estimated using the R package "nlme."

\section{Results and Discussion}

Our results demonstrated that GDP increased dramatically in these periods for these two cities. In contrast, the trends of lake area for lakes larger than 20 ha, which contributed most of surface areas of
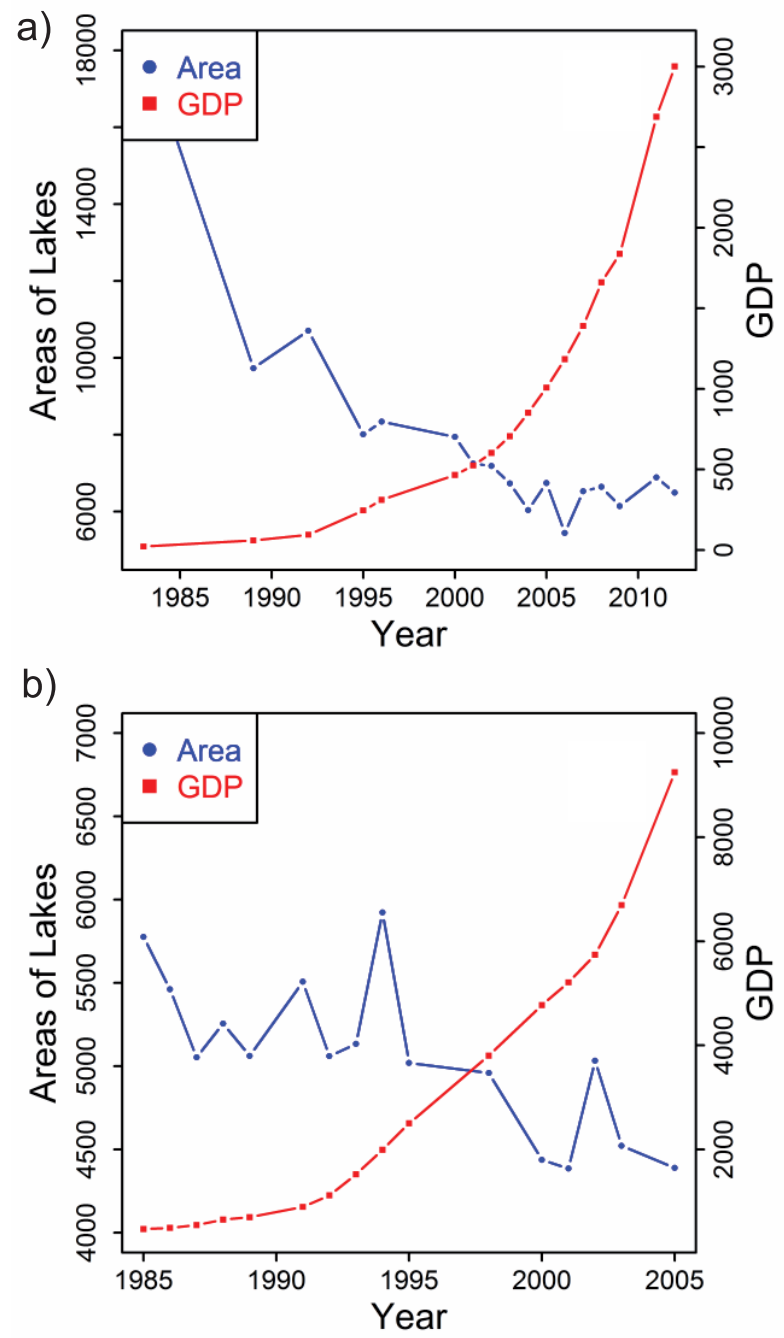

Fig. 2. Trends of changes for GDP (red lines; 100 million RMB) and lake areas (blue lines; ha) for lakes larger than 20 ha in Nanchang a) and Shanghai b). 
Table 1. The pseudo- $\mathrm{r}^{2}$ and AIC for the time series auto-regressive generalized least square (GLS) models of lake's areas/numbers and annual precipitation (PRE), mean annual temperature (TEM), population size (POP), gross domestic product (GDP), primary industry (GDP1), secondary industry (GDP2), and tertiary industry (GDP3). A1, A2 and A3, N1, N2, and N3 represent areas and numbers of lakes with area scales of 5 ha to 10 ha, 10 ha to 20 ha, and larger than 20 ha, respectively. Var is the variables we used in the study. The bold texts for $p$ seudo- $r^{2}$ represent the significance at $\mathrm{p}<0.05$ level for the coefficients in GLS models. The symbols in brackets represent the trends of coefficients in GLS models, and "+" means the variables positively related to lakes' areas/numbers and "-" means negative.

\begin{tabular}{|c|c|c|c|c|c|c|c|c|c|c|c|c|}
\hline \multirow{2}{*}{ Var } & \multicolumn{2}{|c|}{ N1 } & \multicolumn{2}{|c|}{ A1 } & \multicolumn{2}{|c|}{$\mathrm{N} 2$} & \multicolumn{2}{|c|}{$\mathrm{A} 2$} & \multicolumn{2}{|c|}{ N3 } & \multicolumn{2}{|c|}{ A3 } \\
\hline & pseudo-r ${ }^{2}$ & AIC & pseudo- $r^{2}$ & AIC & pseudo- $r^{2}$ & AIC & pseudo- $\mathrm{r}^{2}$ & AIC & pseudo- $\mathrm{r}^{2}$ & AIC & pseudo-r ${ }^{2}$ & AIC \\
\hline \multicolumn{13}{|c|}{ Shanghai } \\
\hline GDP & $0.34(+)$ & 9.05 & $0.34(+)$ & 11.30 & $0.38(-)$ & 18.53 & $0.37(-)$ & 25.33 & $0.67(-)$ & 11.52 & $0.51(-)$ & -35.97 \\
\hline GDP1 & $0.34(+)$ & 9.20 & $0.34(+)$ & 11.34 & $0.40(-)$ & 17.75 & $0.42(-)$ & 24.04 & $0.66(-)$ & 11.69 & $0.48(-)$ & -34.86 \\
\hline GDP2 & $0.33(+)$ & 9.41 & $0.32(+)$ & 11.64 & $0.38(-)$ & 18.60 & $0.37(-)$ & 25.40 & $0.66(-)$ & 12.06 & $0.50(-)$ & -35.77 \\
\hline GDP3 & $0.36(+)$ & 8.52 & $0.36(+)$ & 10.76 & $0.38(-)$ & 18.20 & $0.38(-)$ & 25.02 & $0.67(-)$ & 11.28 & $0.50(-)$ & -35.82 \\
\hline POP & $0.34(+)$ & 9.24 & $0.32(+)$ & 11.55 & $0.42(-)$ & 18.77 & $0.40(-)$ & 25.25 & $0.56(-)$ & 16.07 & $0.50(-)$ & -35.69 \\
\hline PRE & $0.01(-)$ & 14.02 & $0.00(+)$ & 16.22 & $0.25(+)$ & 18.10 & $0.25(+)$ & 23.63 & $0.00(-)$ & 24.61 & $0.02(+)$ & -27.70 \\
\hline TEM & $0.12(+)$ & 13.47 & $0.12(+)$ & 15.67 & $0.10(-)$ & 25.85 & $0.13(-)$ & 30.86 & $0.31(-)$ & 20.56 & $0.16(+)$ & -29.16 \\
\hline \multicolumn{13}{|c|}{ Nangchang } \\
\hline GDP & $0.39(-)$ & 0.15 & $0.40(-)$ & -0.49 & $0.40(-)$ & 0.14 & $0.00(-)$ & 36.60 & $0.79(-)$ & -14.34 & $0.73(-)$ & -18.08 \\
\hline GDP1 & $0.41(-)$ & -0.18 & $0.43(-)$ & -0.87 & $0.42(-)$ & -0.14 & $0.00(-)$ & 36.59 & $0.80(-)$ & -13.48 & $0.76(-)$ & -18.28 \\
\hline GDP2 & $0.37(-)$ & 0.60 & $\mathbf{0 . 3 8}(-)$ & 0.00 & $0.38(-)$ & 0.49 & $0.00(-)$ & 36.61 & $0.77(-)$ & -13.71 & $0.70(-)$ & -16.94 \\
\hline GDP3 & $0.44(-)$ & -0.88 & $0.45(-)$ & -1.57 & $0.44(-)$ & -0.73 & $0.00(-)$ & 36.59 & $0.83(-)$ & -15.76 & $0.79(-)$ & -21.13 \\
\hline POP & $0.38(-)$ & 0.46 & $\mathbf{0 . 3 8}(-)$ & -0.09 & $\mathbf{0 . 3 9}(-)$ & 0.26 & $0.01(-)$ & 36.61 & $0.77(-)$ & -14.53 & $0.71(-)$ & -17.29 \\
\hline PRE & $0.08(+)$ & 5.20 & $0.08(+)$ & 5.05 & $0.14(+)$ & 4.87 & $0.00(+)$ & 36.44 & $0.08(-)$ & 1.34 & $0.10(+)$ & 0.10 \\
\hline TEM & $0.09(-)$ & 5.07 & $0.09(-)$ & 4.88 & $0.13(-)$ & 4.27 & $0.04(+)$ & 36.52 & $0.30(+)$ & 1.45 & $0.25(-)$ & -7.63 \\
\hline
\end{tabular}

lakes, were reduced (Fig. 2). The results of univariate regression analyses show that gross domestic product (GDP), including primary industry (GDP1), secondary industry (GDP2), and tertiary industry (GDP3), were all significantly negatively correlated with the number and areas of lakes in Shanghai and Nanchang for all sizes of lakes, except for lake areas for the lakes with areas between 10 ha and 20 ha (size level 2) in Nanchang (not significant) and positively significantly correlated with the number and areas of lakes with areas between 5 ha to 10 ha (Table 1). Annual precipitation (PRE) was significantly correlated with lake areas for sizes larger than 10 ha and lower than 20 ha, and PRE was also significantly correlated with the number of lakes at size level 2 in Shanghai. Meanwhile, mean annual temperature (TEM) was significantly correlated with a number of lakes with areas at level 3 (lake area larger than 20 ha) in Shanghai (Table 1).

We performed OLS and GLS regression analyses for GDP versus the lake areas at level 3 (areas larger than $20 \mathrm{ha}$ ), which represented the highest proportion among all lakes (Fig. 3). The results show that the logarithmic regression model can explain $73.27 \%$ of the variance in lake areas of Nanchang and $50.82 \%$ for Shanghai, respectively. In the initial years of Chinese Economic
Reform and the associated economic development, the areas of large lakes (larger than 20 ha, which represent a majority of lake areas) decreased dramatically. However, the rate of this decrease slowed beginning in the 1990s. For lakes with areas larger than 20 ha, the GDP and population size always has a relatively high pseudo-r ${ }^{2}$ with low AICs (Table 1), but the PRE and TEM are not.

Wetland is the most important landscape type in the world, and it also has unique ecosystem functions for cities and is one of most vulnerable ecological types [23]. Lakes are an important type of wetland, and it has been inferred that climate change and human activities are important factors in lake area reductions [5, 24]. However, there have been limited studies that show the relative effects of these two factors on the lakes in big cities. Using satellite images from Landsat sensors, we found that indices of economic development (i.e., GDP and population size) were important for almost all lake area sizes in the two cities, except for the lakes with areas between 10 ha and 20 ha. However, climate change exhibited smaller effects on lake size (Table 1). Even relatively pristine areas with less human activities such as Inner Mongolia and central China (e.g., Baiyangdian) experienced lake reductions due to human activities, e.g., coal mining and irrigation [5, 24]. Our results show 
that the lakes in these large cities were also mainly affected by human activities. However, the climatic factors significantly affected the areas of large lakes in Shanghai (Table 1). Our results indicated that human activities are the driving factors of lake shrinkage in cities. Below, we further discuss the anthropogenic activities and climate change shaping this shrinkage.

Firstly, population size is related to water consumption [6,9]. With population size increasing, water consumed by cities increases [9]. A previous study estimated that the water footprint in China was $200 \mathrm{~m}^{3} / \mathrm{cap} / \mathrm{yr}$ in the period 1997-2001 [9]. In the past three decades, the populations of these two cities grew very quickly. For example, the population of Shanghai increased from 12 million in 1985 to 18 million in 2005 (www.shanghai.gov.cn), and the population of Nanchang increased from 3 million in 1983 to 5 million in 2012 (http://www.yearbookchina.com). Thus, water consumption has also likely grown due to increased population size, and this may have subsequently affected lake surface areas directly and indirectly.
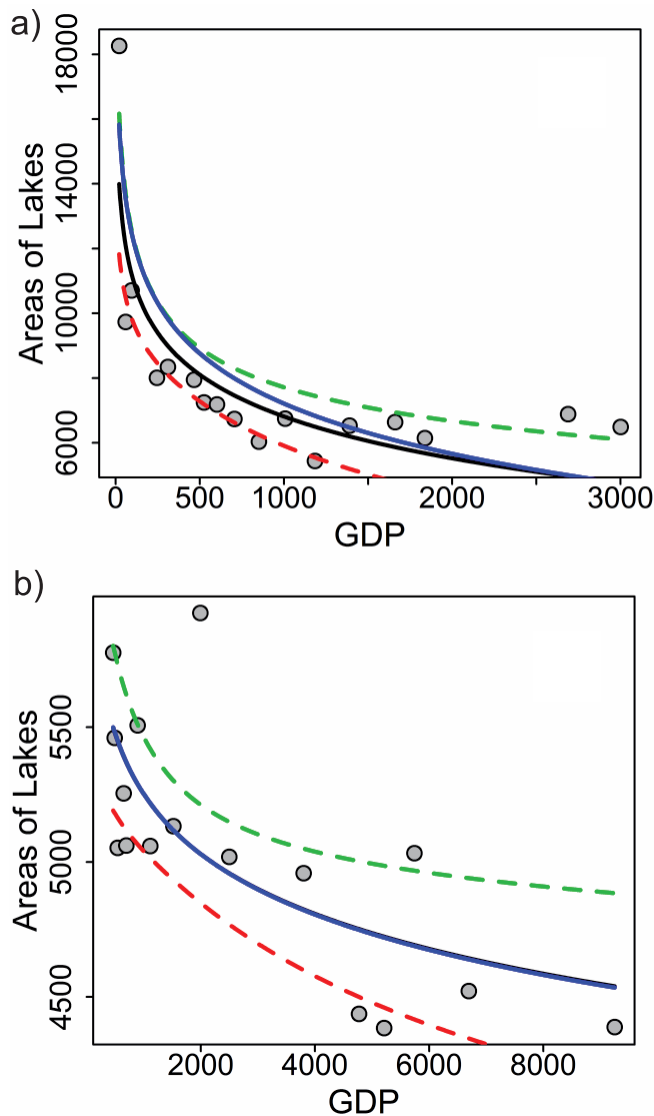

Fig. 3. Nonlinear regression between GDP and lake areas for lakes larger than 20 ha in Nanchang a) and Shanghai b). The unit for the areas of lakes is ha, and for GDP is 100 million China Yuan (RMB). The black lines are the fitted lines for ordinary least squares (OLS) models, and the dashed lines are their $95 \%$ confidence intervals. The blue lines are the fitted lines for time series auto-regressive generalized least squares (GLS) models. (Note that the fitted line from GLS model for Shanghai is almost overlapped by the line from OLS.)
Secondly, land use change may place pressure on wetlands through changes in hydrology [25]. As a developing country, the size of cities in China has expanded swiftly in the past three decades. With urbanization, lakes are altered by urban development via the physical changes of construction. The boundaries of all metropolitan cities have extended, and land use/land cover changed with the city expansion $[17,18]$. In this urban development, lakes might be filled and replaced with other types of landscapes. Thus, the lake areas have been reduced partly because of the landscape change due to physical construction. For example, the urbanized area of Shanghai changed from $111.8 \mathrm{~km}^{2}$ in 1947 to $269 \mathrm{~km}^{2}$ in 1996 [26], and this land cover change has potentially affected the lake areas/abundances in cities.

Thirdly, water resources are one of the main determinants of economic development, and the stability of water supply is a prerequisite for the economy [27]. On the other hand, water consumption is related to economic development, including economic aggregate and structure, and thereby affects the wetlands. In the past three decades, the economies of these two large cities also developed very quickly within the context of China's quickly developing economy. The GDP of Nanchang grew from 2 billion RMB in 1983 to 300 billion RMB in 2012, and the GDP
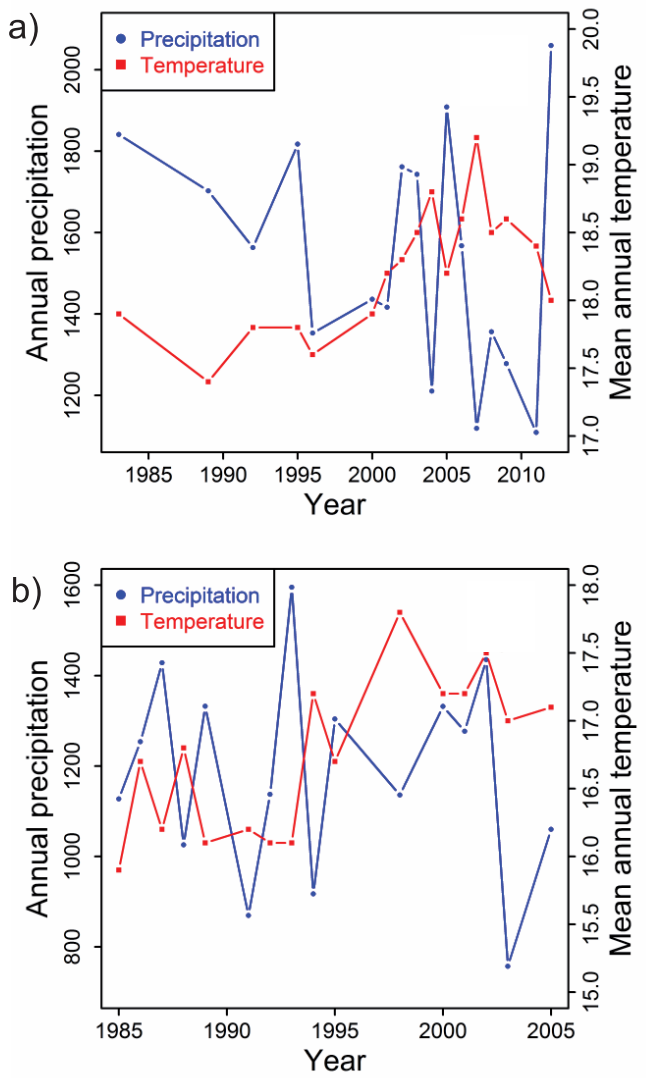

Fig. S1. Mean annual temperature and annul precipitation for Nanchang a) and Shanghai b) (the unit for annual precipitation is $\mathrm{mm}$, and for mean annul temperature is ${ }^{\circ} \mathrm{C}$ ). 
of Shanghai grew from 47 billion RMB in 1985 to 925 billion in 2005. Evidence indicates that the growth in water consumption was also closely related to the industrial revolution [28]. With these developments, especially with the development of industry, the GDP2 for Nanchang and Shanghai increased by more than one hundred times. The water consumption for GDP2 has been increased dramatically with this super industry development. This consumption and human construction all may determine reductions in the area and number of lakes. Meanwhile, we also found that the rate of lake area decrease slowed with increasing GDP. These two variables do not exhibit a linear relationship (Fig. 3). Thus, we should pay more attention to protecting wetlands while cities are in the initial development periods. This may be much more important for the cities in a rapidly developing country like in China, and if we can pay enough attention in the early development stage, the price of lake conservation will be much lower. Our results also demonstrated that in these two cities, the effects of human actives and climate change are relatively consistent on the area/ abundance of lakes, and (Table 1) even these two cities have different human disturbance histories.

During the period from the 1980 s to the 2010s, the temperatures in these two cities generally increased (Fig. S1). However, these variations could not explain much variation in lake areas, except for the largest lakes in Shanghai (Table 1). Meanwhile, the correlations of lake areas with temperatures and precipitation levels were not statistically significant. Our results show that the main determinants of lake area reductions, especially for large lakes, are local human activities rather than climate change. In the past century, the climate has changed in many places. Temperatures have increased and precipitation has shifted temporally and spatially [29]. In China, it is clear that temperatures have increased, which subsequently influenced the local water resources in recent decades [15]. Even for these two cities, the annual temperature and precipitation have changed over the past three decades (Fig. S1). Given this background, climate change might also influence the water available for lakes. However, the wetlands in cities are dramatically disturbed by humans and are more complex than lakes in relatively natural environs.

\section{Conclusions}

Based on our results, compared with climate change, human activities are more important in explaining the changes of lakes in the large cities in eastern China. Our results also demonstrated that since the main determinants are human activities at the local scale, cities may have the ability to protect wetlands via suitable planning.

\section{Appendix}

Table S1. Data source and acquired time of satellite images for Nanchang (USGS is United States Geological Survey - http://glovis. usgs.gov).

\begin{tabular}{|c|c|c|c|}
\hline Acquired time & Landsat Archive & Sensors & Data source \\
\hline $1983 / 9 / 9$ & LM41210401983332FFF03 & Landsat4-present & USGS \\
\hline $1989 / 7 / 15$ & LT51210401989196BJC00 & Landsat4-5TM & USGS \\
\hline $1992 / 4 / 2$ & LT51210401992093BKT00 & Landsat4-present & USGS \\
\hline $1995 / 9 / 2$ & LT51210401995245CLT00 & Landsat4-5TM & USGS \\
\hline $1996 / 9 / 4$ & LT51210401996248CLT00 & Landsat4-5TM & USGS \\
\hline $2000 / 9 / 15$ & LT51210402000259BJC00 & Landsat4-5TM & USGS \\
\hline $2001 / 6 / 30$ & LT51210402001181BJC02 & Landsat4-5TM & USGS \\
\hline $2002 / 10 / 7$ & LT51210402002280BJC00 & Landsat4-5TM & USGS \\
\hline $2003 / 9 / 24$ & LT51210402003267BJC00 & Landsat4-5TM & USGS \\
\hline $2004 / 8 / 9$ & LT51210402004222BJC00 & Landsat4-5TM & USGS \\
\hline $2005 / 8 / 12$ & LT51210402005224BJC00 & Landsat4-5TM & USGS \\
\hline $2006 / 11 / 3$ & LT51210402006307BJC01 & Landsat4-5TM & USGS \\
\hline $2007 / 7 / 25$ & LT51210402007278BKT01 & Landsat4-5TM & USGS \\
\hline $2008 / 7 / 27$ & LT51210402008137BKT00 & Landsat4-5TM & USGS \\
\hline $2009 / 10 / 2$ & LT51210402009299BKT00 & Landsat4-5TM & USGS \\
\hline $2011 / 8 / 2$ & LT51210402011209BKT00 & Landsat4-5TM & USGS \\
\hline $2012 / 7 / 22$ & LE71210402012204EDC00 & Landsat4-5TM & USGS \\
\hline
\end{tabular}


Table S2. Data source and acquired time of satellite images for Shanghai.

\begin{tabular}{|c|c|c|c|}
\hline Acquired time & Landsat Archive & Sensors & Data source \\
\hline $1985 / 11 / 20$ & LT51180381985324HAJ00 & Landsat4-5TM & USGS \\
\hline $1986 / 8 / 19$ & LT51180381986231HAJ00 & Landsat4-5TM & USGS \\
\hline $1987 / 11 / 10$ & LM51180381987314HAJ00 & Landsat4-Present & USGS \\
\hline $1988 / 7 / 7$ & LT51180381988189HAJ00 & Landsat4-5TM & USGS \\
\hline 1989/8/11 & LT51180381989223HAJ01 & Landsat4-5TM & USGS \\
\hline $1990 / 5 / 10$ & LT51180381990130HAJ00 & Landsat4-5TM & USGS \\
\hline $1991 / 10 / 20$ & LT51180381991293BJC00 & Landsat4-5TM & USGS \\
\hline $1992 / 8 / 3$ & LT51180381992216HAJ00 & Landsat4-5TM & USGS \\
\hline $1993 / 6 / 3$ & LT51180381993154HAJ01 & Landsat4-5TM & USGS \\
\hline $1994 / 3 / 2$ & LT51180381994061HAJ00 & Landsat4-5TM & USGS \\
\hline $1995 / 8 / 12$ & LT51180381995224HAJ00 & Landsat4-Present & USGS \\
\hline $1998 / 8 / 4$ & LT51180381998216HAJ00 & Landsat4-5TM & USGS \\
\hline $2000 / 6 / 14$ & LE71180382000166SGS00 & L7 SLC-on(1999-2003) & USGS \\
\hline $2001 / 7 / 3$ & LE71180382001184EDC00 & L7 SLC-on(1999-2003) & USGS \\
\hline $2002 / 10 / 2$ & LT51180382002275BJC00 & Landsat4-5TM & USGS \\
\hline $2003 / 10 / 29$ & LE71180382003302HIJ00 & Landsat4-Present & USGS \\
\hline $2005 / 8 / 15$ & LE71180382005227EDC00 & Landsat4-Present & USGS \\
\hline
\end{tabular}

\section{Acknowledgements}

We thank Zhongyue Wang, Wenxin Li, Yilu Ren, Yueya Zhang, Dandan Jing, Prof. Mingyang Li, $\mathrm{Cao} \mathrm{Yu}$, and Yufeng Yang for contributing to data collection. The research was financially supported by the China National R \& D Program 'Building Strong Ecological Security Patterns Through Elevating Green Infrastructure's Level of Ecosystem Services' (No. 2017YFC0505705) and the National Natural Science Foundation of China (No. 31170660). We also thank the editor and two anonymous reviewers for their comments.

\section{Conflict of Interest}

The authors declare no conflict of interest.

\section{References}

1. MENG W., ZHANLEI W.U., WANG Z. Control factors and critical conditions between carbon sinking and sourcing of wetland ecosystem (In Chinese with English Abstract). Ecol. Environ. Sci. 20, 1359, 2011.

2. CLARKSON B.R., AUSSEIL A.G.E., GERBEAUX P. DYMOND J.R. Wetland ecosystem services. In Ecosystem services in New Zealand: Conditions and Trends (ed. Dymond J.), The Caxton Press, Christchurch, New Zealand. 192, 2013.
3. MCLAUGHLIN D., COHEN M.J. Realizing ecosystem services: Wetland hydrologic function along a gradient of ecosystem condition, Ecol. Appl., 23, 1619, 2013.

4. LIU D., CAO C. CHEN W., NI X., TIAN R., XING X. Monitoring and predicting the degradation of a semi-arid wetland due to climate change and water abstraction in the Ordos Larus relictus National Nature Reserve, China, Geomat. Nat. Haz. Risk. 8, 367, 2016.

5. TAO S., FANG J., ZHAO X., ZHAO S., SHEN H., HU H., TANG Z., WANG Z., GUO Q. Rapid loss of lakes on the Mongolian Plateau, P. Natl. Acad. Sci. USA, 112, 2281, 2015.

6. HOEKSTRA A.Y., CHAPAGAIN A.K. Water footprints of nations: Water use by people as a function of their consumption pattern, in Integrated Assessment of Water Resources and Global Change, Springer, Netherlands, 35, 2006.

7. LIU J., YANG W. Water sustainability for China and beyond, Science, 337, 649, 2012.

8. MICHISHITA R., JIANG Z., XU B. Monitoring two decades of urbanization in the Poyang Lake area, China through spectral unmixing, Remote Sens. Environ., 117, 3, 2012.

9. OKI T., KANAE S. Global hydrological cycles and world water resources, Science, 313, 1068, 2006.

10. MU Q., ZHAO M., RUNNING S. W. Evolution of hydrological and carbon cycles under a changing climate. Part III: global change impacts on landscape scale evapotranspiration, Hydrol. Process, 25, 4093, 2011.

11. PATENAUDE T., SMITH A.C., FAHRIG L. Disentangling the effects of wetland cover and urban development on quality of remaining wetlands, Urban Ecosyst., 18, 663, 2015. 
12. KOOP S.H.A., LEEUWEN C.J.V. The challenges of water, waste and climate change in cities, Environ. Dev. Sustain., 19, 385, 2017.

13. MAGANA V., ZERMENO D., NERI C. Climate change scenarios and potential impacts on water availability in Northern Mexico, Clim. Res., 51, 171, 2012.

14. YUAN X., MU R., ZUO J., WANG Q. Economic development, energy consumption, and air pollution: A critical assessment in China, Human and Ecological Risk Assessment: An International Journal, 21, 781, 2015.

15. PIAO S., CIAIS P., HUANG Y., SHEN Z., PENG S., LI J., ZHOU L., LIU H., MA Y., DING Y., FRIEDLINGSTEIN P., LIU C., TAN K., YU Y., ZHANG T., FANG J. The impacts of climate change on water resources and agriculture in China, Nature, 467, 43, 2010.

16. DHAKAL S. Urban energy use and carbon emissions from cities in China and policy implications, Energ. Policy, 37, 4208, 2009

17. SONG X., CHANG K., YANG L. SCHEFFRAN J. Change in environmental benefits of urban land use and its drivers in Chinese cities, 2000-2010, Int. J. Env. Res. Pub. He., 13, 535, 2016.

18. YIN J., YIN Z., ZHONG H., XU S., HU X., WANG J., WU J. Monitoring urban expansion and land use/land cover changes of Shanghai metropolitan area during the transitional economy (1979-2009) in China. Environ. Monit. Assess., 177, 609, 2011.

19. ZHANG H., WANG Q., LI G., ZHANG H., ZHANG J. Losses of ecosystem service values in the Taihu Lake Basin from 1979 to 2010. Front. Earth Sci., 11, 1, 2017.

20. BOX G. E., JENKINS G. M., REINSEL G. C., LJUNG G. M. Time series analysis: forecasting and control, John Wiley \& Sons, 2015.
21. AKAIKE H. A new look at the statistical model identification, IEEE transactions on automatic control, 19, 716, 1974

22. R CORE TEAM. R: A language and environment for statistical computing - $\mathrm{R}$ Foundation for Statistical Computing. Vienna, Austria. (www. R-project.org), 2015.

23. CLARKSON B.R., AUSSEIL A.E., GERBEAUX P. Wetland ecosystem services (Chapter in Ecosystem services in New Zealand), Manaaki Whenua Press, 2013.

24. 2LIU C., XIE G., HUANG H. Shrinking and drying up of Baiyangdian lake wetland: a natural or human cause? Chinese Geogr. Sci., 16, 314, 2006.

25. FERRATI R., CANZIANI G.A., MORENO D.R. Estero del Ibera: hydrometeological and hydrological characterization, Ecol. Model., 186, 3, 2005.

26. REN W., ZHONG Y., MELIGRANA J., ANDERSON B. WATT W. E., CHEN J., LEUNG H. L. Urbanization, land use, and water quality in Shanghai: 1947-1996, Environ. Int., 29, 649, 2003.

27. WEI J., WEI J., WESTERN A. Evolution of the societal value of water resources for economic development versus environmental sustainability in Australia from 1843 to 2011, Global Environ. Chang. 42, 82, 2017.

28. PASKIN P.D., HANSEN E., MARGOLLIS R.M. Water and sustainability, Nat. Resour. Forum, 20, 1, 1996.

29. JIANG R. GAN T.Y., XIE J., WANG N., KUO C.C. Historical and potential changes of precipitation and temperature of Alberta subjected to climate change impact: 1900-2100, Theor. Appl. Climatol., 127, 1, 2017. 